\title{
Adverse drug reactions in hospitalized Colombian children
}

\section{Reacciones adversas a medicamentos en niños hospitalizados en Colombia}

\author{
Roxana de las Salas ${ }^{1}$, Daniela Díaz-Agudelo ${ }^{1}$, Francisco Javier Burgos-Flórez ${ }^{2}$, Claudia Vaca ${ }^{3}$, Dolores Vanessa Serrano-Meriño ${ }^{1}$ \\ ${ }^{1}$ Grupo de Investigación en Enfermería, Departamento de Enfermería, Universidad del Norte, Barranquilla, Colombia \\ ${ }^{2}$ Biomimetics Laboratory, Instituto de Biotecnología Universidad Nacional de Colombia, Bogota, Colombia \\ ${ }^{3}$ Departamento de Farmacia, Universidad Nacional de Colombia, Bogotá, Colombia.
}

De las Salas R, Díaz-Agudelo D, Vaca C, Burgos-Flórez FJ, Serrano-Meriño DV. Adverse drug reactions in hospitalized Colombian children. Colomb Med (Cali). 2016; 47(3): 142-7

(C) 2016. Universidad del Valle. This is an Open Access article distributed under the terms of the Creative Commons Attribution License, which permits unrestricted use, distribution, and reproduction in any medium, provided the original author and source are credited.

\section{Article history:}

Received: 11 January 2016

Revised: 03 June 2016

Accepted: 17 July 2016

Keywords:

Drug-related side effects, adverse reactions, pharmacovigilance, child, drug monitoring, Colombia

Palabras clave:

efectos secundarios relacionados con los medicamentos, reacciones adversas, farmacovigilancia, niño, monitoreo de fármacos, pediatria, riesgo, Colombia

\begin{abstract}
Resumen

Introduction: The occurrence of adverse drug reactions is an Introducción: La aparición de reacciones adversas a medicamentos es important issue due to the lack of drug safety data in children. un tópico importante debido a la escasa información sobre seguridad Objective: To describe the Adverse Drug Reactions in inpatient de medicamentos en niños.

children under 6 years of age in two general pediatrics wards located Objetivo: Describir las reacciones adversas a medicamentos en niños in Barranquilla, Colombia. menores de 6 años de edad hospitalizados en dos servicios de pediatría Methods: A prospective cohort study based on intensive general en Barranquilla, Colombia.

pharmacovigilance was conducted during six months in order to Métodos: Estudio prospectivo de una cohorte de pacientes basado monitor the emergence of Adverse Drug Reactions in inpatients en farmacovigilancia intensiva, realizado durante seis meses para children under 6 years of age with at least one medication prescribed. monitorizar la aparición de reacciones adversas a medicamentos en The study was conducted in two pediatric wards of two hospitals niños menores de 6 años de edad hospitalizados y con indicación de located in Barranquilla, Colombia. Naranjo's Algorithm was used al menos un medicamento. El estudio fue conducido en dos servicios to evaluate imputability, the modified Hartwig and Siegel assessment de pediatría general de dos hospitales en Barranquilla, Colombia. El scale to establish severity and the Schumock and Thornton criteria to algoritmo de Naranjo fue usado para evaluar imputabilidad, la escala determine preventability.

modificada de Hartwig y Siegel para establecer severidad y los criterios Results: Of a total of 772 monitored patients, 156 Adverse Drug de Schumock y Thornton para determinar evitabilidad.

Reactions were detected on 147 children. The cumulative incidence of Resultados: En total se monitorizaron 772 pacientes. Se detectaron Adverse Drug Reactions was 19.0\% (147/772); the incidence density 156 reacciones adversas a medicamentos en 147 niños. La incidencia was 37.6 Adverse Drug Reactions per 1,000 patients-days (147/3,913). acumulada de las reacciones adversas a medicamentos fue $19.0 \%$ The frequency was higher in children under 2 years of age (12.7\%). (147/772); la densidad de incidencia fue de 37.6 reacciones adversas Emergence of Adverse Drug Reactions was higher in male patients a medicamentos por 1,000 pacientes-día (147/3,913). La frecuencia $(\mathrm{RR}=1.66 ; 95 \% \mathrm{CI}=1.22-2.22, p=0.001)$ and in those who used de reacciones adversas fue mayor en niños $<2$ años de edad $(12.7 \%)$. systemic antibiotics $(\mathrm{RR}=1.82 ; 95 \% \mathrm{CI}=1.17-2.82, p=0.005) . \quad$ La ocurrencia de reacciones adversas a medicamentos fue mayor en Conclusions: Adverse Drug Reactions are common among pacientes masculinos ( $R R=1.66$; IC 95\% $=1.22-2.22$, $p=0.001)$ y en hospitalized children and represent an additional burden of morbidity quienes usaron antibióticos sistémicos ( $\mathrm{RR}=1.82 ; \mathrm{IC} 95 \%=1.17-2.82$, and risk, particularly in those who used several medicines, including $p=0.005)$.

antibiotics.

Conclusiones: Las reacciones adversas a medicamentos son comunes en niños hospitalizados y representan una morbilidad adicional y mayor riesgo, particularmente en aquellos que usaron varios medicamentos, incluyendo antibióticos.
\end{abstract}

\section{Corresponding author:}

Roxana De las Salas. Departamento de Enfermería, Universidad del Norte, Barranquilla, Colombia. Km 5 Vía Puerto Colombia, Phone: +57 53509509. E-mail: rdelassalas@uninorte.edu.co 


\section{Introduction}

The troubles related to pharmacological research in children have generated lack of drug safety and efficacy information ${ }^{1,2}$. Despite the effort of National and International authorities to stimulate the notification of Adverse Drug Reactions (ADRs), under-reporting is still quite common ${ }^{3}$. Therefore, Intensive Pharmacovigilance is considered an important issue in pediatric population, particularly because of its increased susceptibility to $\mathrm{ADRs}^{4,5}$ and predisposing factors ${ }^{6}$. Intensive pharmacovigilance is the systematic monitoring of the occurrence of adverse events resulting from drug use during the entire length of prescription ${ }^{7}$. According to the WHO, an ADR is "a response which is noxious and unintended, and which occurs at doses normally used in humans for the prophylaxis, diagnosis, or therapy of disease, or for the modification of physiological function" ${ }^{\text {. }}$

The WHO Global Individual Case Safety Report (ICSR) database (VigiBase ${ }^{\circledR}$ ) has reported ADRs rates of $7.7 \%(268,145)$ in children from 0 to 17 years of age 9 . However, these reports did not specify the frequency of ADRs in children under 6 years of age and seemed to show underestimated rates, as other studies have reported higher incidences ${ }^{10}$. In addition, younger ages (children from 1 month to 2 years old), male sex, prolonged and previous hospitalization, indication of antibiotics and a higher number of prescribed drugs are factors associated with a higher risk of ADRs ${ }^{10,11}$. In the case of Colombia, no specific data about ADRs frequency and characteristics has been described for this population, which is considered a priority in the sustainable development goals. Thus, the aim of this study was to describe the Adverse Drug Reactions in inpatient children under 6 years of age in two general pediatrics wards located in Barranquilla, Colombia.

\section{Materials and Methods}

Study design and participants

A prospective cohort study based on intensive pharmacovigilance was conducted during 6 months from June to December 2013 in two general pediatrics wards of two Colombian teaching hospitals in Barranquilla (city of the Colombian Caribbean Coast). One hospital was public with 29-bed capacity pediatric units, two of which are used for isolated patients. The other hospital was private and included 20 bed capacity pediatric units, from which isolation beds are assigned on a need basis. Both institutions admit patients between 1 month and 17 years of age.

We included pediatric patients $<6$ years of age without ADRs which were hospitalized at least 24 hours and had at least one prescribed medication. Patients who did not meet the last inclusion criteria, or those whose parents did not authorize participation, or were admitted only for taking diagnostic test or referred from other institutions, were excluded. In addition, we did not monitored side effects associated with the administration of intravenous solutions, contrast media, nutraceuticals and topical products (dermatological and ophthalmic). Thus, we only monitored those drugs which contained active ingredients used for the treatment of illness.

During the monitoring period, 777 patients were admitted in the general pediatrics wards, of which 5 were excluded for being released before completing 24 hours of hospitalization. For this reason, we included 772 pediatrics patients $<6$ years of age.
Data collection

Once the study protocol was approved by the hospitals directive board, we initiated data collection with a one week pilot before follow up. The pilot allowed the improvement of different aspects of the collecting form designed by the researchers. Children's parents were informed about the research objectives and a signed informed consent form was required to allow participation.

A clinical nurse was instructed and trained in the detection of suspected ADRs in order to collect the data from all the patients that were admitted during the research period. A two sections instrument was used for data collection. The first section consisted of a questionnaire applied to children's parents, which included sociodemographic variables (gestational age, birth weight and height), personal and family medical history, information about medicines previously used and admission causes. The second section was an adaptation of the Formato para Reporte de Sospecha de Eventos Adversos a Medicamentos (FOREAM) made by the Instituto de Vigilancia de Medicamentos y Alimentos (INVIMA), which is similar to The Yellow Card Scheme. This form was used for collecting drug use data from nursing, medical and clinical laboratory tests records found on patients medical history.

We determined suspected ADRs cases according to the International Conference on Harmonisation (ICH), which defined a suspected ADR as "any deviation of the expected clinical status (signs, symptoms and other clinical and laboratory findings)"12. When we suspected an ADR, we collected the information related to the onset and duration of symptoms, number of prescribed medicines to treat the ADR (e.g. antihistamines and corticosteroids), dose adjustment, treatment interruptions and patient outcome. In addition, all data associated with the detected changes was verified with pediatricians and nurses in charge.

Daily visits to the wards were conducted to identify new admissions, interview parents, detect suspected ADRs and take part on medical rounds. In other words, we developed an intensive drug monitoring plan from admission till patient discharge date, which was based on patient-centered intensive pharmacovigilance.

Once we finished gathering data from suspected ADRs, we employed Naranjo's algorithm to evaluate the temporal relationship and the biological/pharmacological plausibility between drug exposure and suspected ADR emergence. This let us establish imputability between drugs and suspected ADRs. Naranjos's algorithm classifies ADRs as doubtful (0), possible (1-4 points), probable (5-8 points) and definite ( $\geq 9)^{13,14}$. Meanwhile, The severity of ADRs was assessed with the Modified Hartwig and Siegel Assessment Scale ${ }^{15}$, which classifies ADRs as mild (uncomplicated primary disease which does not require treatment or the discontinuation of treatment), moderate (signs and symptoms appear but the functionality of organs and systems are not affected, but may require drug treatment) or severe (lifethreatening symptoms or systemic organic dysfunction which require hospitalization or prolonged hospital stay and cause disability, persistent failure or defects, reduction of life expectancy or death). The Modified Schumock and Thornton's criteria ${ }^{16}$ were used to establish ADRs preventability, in which an ADR was considered preventable when one or more of the questions defined in this tool, were affirmatively answered. The ADRs were 
classified according to the affected organ systems (integumentary, hematological, nervous, digestive, urinary, cardiovascular or respiratory). The multidisciplinary team employed for analyzing imputability, severity and preventability of suspected ADRs was formed by a pharmacist, a nurse, a pharmacologist and a pediatrician. The identified ADRs and the pharmacological groups related to them were classified according to the Task-force in Europe for Drug Development for the Young (TEDDY) ${ }^{17}$ and The Anatomical Therapeutic Chemical Classification System (ATC) ${ }^{18}$.

Statistical analysis

The collected data was analyzed in the statistical program SPSS (Statistics Statistical Package for the Social Science, v21). ADRs incidence density was estimated. A descriptive analysis of the variables was conducted according to their nature. A crude bivariate relative risk (RR) and 95\% confidence interval (CI) were calculated between the dependent variable, which was the presence or absence of ADRs, and different independent variables. A Chi-square test, with a significance level of $p<0.05$, was also performed between the dependent variable and each independent one.

Ethical considerations

The protocol was approved by the Research Ethics Committee of the Health Care Division of the "Universidad del Norte" and was declared as minimal risk by the researchers. Likewise, the protocol was conducted under the human research ethical criteria defined in the Resolución 008430 de 1993 of the Ministerio de Salud $y$ Protección Social de Colombia and The Declaration of Helsinki.

\section{Results}

A total of 772 children were involved, of whom $49.1 \%$ were females. The average age was 12 months of age (range from 1 month to 60 months). Sixty point two percent of the children were $<24$ months of age and $46.6 \%$ of children were between 6 and 12 months of age. The most frequent medical diagnoses were: respiratory system diseases $40.7 \%$ (314); urinary tract diseases 22.4\% (173); Skin and subcutaneous tissue disorders $19.2 \%$ (148) and miscellaneous disorders $17.7 \%$ (137) (Table 1).

Table 1. Sociodemographic and clinical characteristics of participants

\begin{tabular}{lrr}
\hline Characteristics & Female N (\%) & Total N (\%) \\
\hline Age (months)* & & \\
$<6$ & $448(5.7)$ & $95(12.3)$ \\
$6--12$ & $186(24.1)$ & $360(46.6)$ \\
$13-24$ & $49(6.3)$ & $112(14.5)$ \\
$25-47$ & $43(5.6)$ & $77(10.0)$ \\
$\geq 48$ & $57(7.4)$ & $128(16.6)$ \\
\hline Medical diagnosis (ICD-10) & & \\
Respiratory system diseases & $146(18.9)$ & $314(40.7)$ \\
Urinary tract diseases & $79(10.2)$ & $173(22.4)$ \\
Skin and subcutaneous tissue disorders & $60(7.8)$ & $148(19.2)$ \\
Miscellaneous & $94(12.2)$ & $137(17.7)$ \\
\hline & Mean (SD) & Mean (SD) \\
Age, months & $20.3(16.7)$ & $20.8(17.3)$ \\
Weight (Kg) & $12.5(6.9)$ & $12.7(7.1)$ \\
Length of hospitalization: Mean (SD) & $5.5(2.4)$ & $5.6(3.3)$ \\
Number of drugs by patient: mean (SD) & $3.8(2.0)$ & $4.1(2.5)$ \\
\hline
\end{tabular}

*Age range of all participants from 1 to 60 months. ICD-10: International Classification of Diseases. SD: standard deviation.
The average length of hospitalization was $5.6 \pm 3.3$ days with a median of 5 days, and $72.2 \%$ had between 2 and 5 prescribed medicines (mean $4.1 \pm 2.5$ ).

Incidence and characteristics of ADRs

A total of 156 ADRs were detected in 147 children, of which 138 children developed just one ADR during their hospitalization and 9 children presented two. The cumulative incidence of ADRs was $19.0 \%(147 / 772)$, with an incidence density of 37.6 ADRs every 1,000 patients -days $(147 / 3,913)$. Furthermore $98.1 \%$ (153) of the ADRs were classified as probable, $1.3 \%$ (2) possible and $0.6 \%$ (1) definite (certain). In addition 98.7\% (154) were not preventable and $1.3 \%$ (2) preventable (these two were related to the rate of administration of vancomycin). In terms of severity, $66.0 \%$ (103) of the ADRs were mild and 34.0\% (53) moderate (Table 2). The most affected organ systems were the digestive, cardiovascular and integumentary. The ADRs did not require treatment in $67.3 \%$ (105) of the cases and none of the patients showed sequels. In all cases, ADRs treatment was the responsibility of physicians.

The therapeutic group that most frequently produced ADRs was systemic antibiotics $70.5 \%$ (110), in which ampicillin, amikacin and clarithromycin represented $43.6 \%$ (Table 3 )

Factors associated with ADRs

The mean age of children that developed ADRs was the same as the ones who did not showed any (Table 4). However, ADRs frequency was higher in children under 2 years of age $(12.7 \%)$ than in children with two or more years of age (6.3\%).

Comparison between Children patients with and without ADRs. The mean length of hospitalization in children who had ADRs

Table 2. Frequency and characteristics of adverse drug reactions

\begin{tabular}{llr}
\hline Characteristics & & $\mathrm{N}(\%)$ \\
\hline $\begin{array}{l}\text { Imputability } \\
\text { (Naranjo`s }\end{array}$ & Definite (Certain) & $1(0.6)$ \\
Algorithm) & Probable & $153(98.1)$ \\
\hline $\begin{array}{l}\text { Preventability } \\
\text { (Schumock and } \\
\text { Thornton criteria) }\end{array}$ & Possible & $23(1.3)$ \\
\hline & Not preventable & $2(1.3)$ \\
& Mild & $154(98.7)$ \\
\hline & Digestive: diarrhea (39), emesis (18), & $103(66.0)$ \\
& Cadominal pain (3), loss of appetite (1) & $61(39.1)$ \\
& Integumentary: rash (4), angioedema (2), & $21(13.5)$ \\
& erythema (2), urticaria (1), skin reaction (1) & $10(6.4)$ \\
& Site o application: phlebitis (6) & $6(3.8)$ \\
& Renal: Increased BUN (1), leg edema (1) & $2(1.3)$ \\
& Nervous: hyperactivity (1), somnolence (1) & $2(1.3)$ \\
$\begin{array}{ll}\text { Severity (Modified } \\
\text { Hartwig and Siegel }\end{array}$ & Hematologic: thrombocytopenia (1) & $1(0.6)$ \\
assessment scale) & Moderate & $5334.0)$ \\
& Digestive: diarrhea (30), emesis (6), & $39(25.0)$ \\
& abdominal pain (2), constipation (1) & \\
Integumentary: angioedema (2), erythema & \\
(2), urticaria (2), maculopapular erythema & $9(5.9)$ \\
(1), rash (1), fever (1) & \\
Renal: Low urine output (1), genital edema (1) & $2(1.3)$ \\
& Site of application: phlebitis (1) & $1(0.6)$ \\
& Nervous: headache (1) & $1(0.6)$ \\
& Hematologic: Thrombocytopenia (1) & $1(0.6)$ \\
\hline
\end{tabular}

ADRs: Adverse Drugs Reactions 
Table 3. Therapeutic groups related to ADRs

\begin{tabular}{llr}
\hline ATC code (n=156 ADRs) & & $\mathrm{N}(\%)$ \\
\hline Antibiotics & Ampicillin & $110(70.5)$ \\
& Amikacin & $27(17.3)$ \\
& Clarithromycin & $26(16.7)$ \\
& Clindamycin & $15(9.6)$ \\
& Cephalothin & $13(8.3)$ \\
& Ceftriaxone & $8(5.1)$ \\
& Ampicillin + Sulbactam & $8(5.1)$ \\
& Others & $4(2.6)$ \\
& Salbutamol & $9(5.8)$ \\
\hline Respiratory system & & $25(16.0)$ \\
\hline \multirow{2}{*}{ Systemic hormonal preparations } & Methylprednisolone & $26(16.0)$ \\
\hline Nervous System & & $7(4.5)$ \\
& Valproic acid & $7(4.5)$ \\
\hline Alimentary tract and metabolism & & $8(5.1)$ \\
& Carbamazepine & $4(2.6)$ \\
& Zinc sulfate & $1(0.6)$ \\
\hline Blood and blood forming organs & & $2(1.3)$ \\
& Diazepam & $1(0.6)$ \\
\hline & Acetaminophen & $1(0.6)$ \\
& & $1(0.6)$ \\
\hline
\end{tabular}

ADRs: adverse drug reactions.

Table 4. Comparison between children patients with and without ADRs

\begin{tabular}{lccc}
\hline Variable & $\begin{array}{c}\text { with ADRs } \\
(\mathrm{N}=147)^{*}\end{array}$ & $\begin{array}{c}\text { without ADRs } \\
(\mathrm{N}=625)^{*}\end{array}$ & $p$ \\
\hline Age (months) & $18.4 \pm 15.8$ & $21.3 \pm 17.5$ & 0.077 \\
Length of hospitalization (days) & $7.1 \pm 5.2$ & $5.3 \pm 2.6$ & 0.001 \\
Number of prescribed drugs & $5.0 \pm 2.5$ & $3.9 \pm 2.4$ & 0.001 \\
$\begin{array}{l}\text { Number of prescribed systemic } \\
\text { antibiotics }\end{array}$ & $2.0 \pm 0.5$ & $1.0 \pm 0.50 .001$ \\
\hline
\end{tabular}

ADRs: adverse drug reactions.

${ }^{*}$ mean \pm standard deviation

was higher (7.1 days \pm 5.2$)$ than those who did not show ADRs (5.3 days $\pm 2.6, p=0.001$ ). The mean of prescribed medicines in children with ADRs was higher than those who did not showed any (mean $5.0 \pm 2.5$ vs $3.9 \pm 2.4$ drugs) $(p=0.001)$. Similarly, the number of prescribed systemic antibiotics in children with ADRs was also higher than in those who were not prescribed any (mean $2.0 \pm 0.5$ vs $1.0 \pm 0.5)(p=0.001)$ (Table 5).

Male patients were more likely to develop ADRs ( $R R=1.32 ; 95 \%$ $\mathrm{CI}=0.96-1.80, p=0.001)$ than female patients. The use of systemic antibiotics was correlated with a higher risk of $\mathrm{ADRs}(\mathrm{RR}=1.82$; (95\% CI $=1.17-2.82, p=0.005)$ than those who did not used an antibiotic (Table 5). 1.5\% (12) of patients with ADRs reported previous ADRs.

\section{Discussion}

This study encompasses an exhaustive collection and evaluation
Table 5. Factors associated to ADRs

\begin{tabular}{|c|c|c|c|c|c|c|c|}
\hline \multirow{2}{*}{ Variables } & & \multirow{2}{*}{$n=772$} & \multicolumn{2}{|c|}{ ADRs } & \multirow{2}{*}{$\begin{array}{c}\text { RR } \\
(95 \% \mathrm{CI})\end{array}$} & \multirow{2}{*}{$\begin{array}{c}\text { Chi } \\
\text { Square }\end{array}$} & \multirow{2}{*}{$\begin{array}{c}p \\
\text { valor }\end{array}$} \\
\hline & & & Yes (\%) & No $(\%)$ & & & \\
\hline \multirow{2}{*}{ Age (yrs) } & $<2$ & 465 & 12.7 & 47.5 & \multirow{2}{*}{$1.32(0.96-1.80)$} & \multirow{2}{*}{3.13} & \multirow{2}{*}{0.07} \\
\hline & $\geq 2$ & 307 & 6.3 & 33.5 & & & \\
\hline \multirow{2}{*}{ Gender } & Female & 393 & 12.0 & 38.9 & \multirow{2}{*}{$1.66(1.22-2.25)$} & \multirow{2}{*}{11.09} & \multirow{2}{*}{0.001} \\
\hline & Male & 379 & 7.0 & 42.1 & & & \\
\hline \multirow{2}{*}{$\begin{array}{l}\text { Previous } \\
\text { ADRs }\end{array}$} & Yes & 42 & 1.5 & 3.9 & \multirow{2}{*}{$1.54(0.93-2.55)$} & \multirow{2}{*}{2.61} & \multirow{2}{*}{0.106} \\
\hline & No & 730.6 & 17.5 & 77.1 & & & \\
\hline \multirow{2}{*}{$\begin{array}{l}\text { Systemic } \\
\text { antibiotic }\end{array}$} & Yes & 600 & 16.4 & 61.3 & \multirow{2}{*}{$1.82(1.17-2.82)$} & \multirow{2}{*}{7.89} & \multirow{2}{*}{0.005} \\
\hline & No & 172.5 & 2.6 & 19.7 & & & \\
\hline
\end{tabular}

ADRs: adverse drug reactions, $n=147$. RR: relative risk. CI: confidence interval.

of ADRs in a cohort of 772 hospitalized pediatric patients. We identified an ADRs incidence of $19.0 \%$, which is higher than the one found by Truner et al. ${ }^{19}$, and Jimenez et al. ${ }^{20}$, demonstrating that children are particularly susceptible to ADRs. The majority of ADRs found were not preventable, as in Temple et al ${ }^{5}$. In order to prevent ADRs, it is advisable to generate strategies that are aimed at improving drug administration safety protocols.

Among the 147 children who presented ADRs, 138 children developed just one and 9 children develop two ADRs. It is noteworthy to mention that children with more than one ADR developed these manifestations at different times. Hence, by exhaustively evaluating patients showing more than one ADR, we concluded that second ADRs were not an extension of the previous ones. Similar data was found by dos Santos and Coelho ${ }^{10}$, who reported that 25 patients developed just one, 5 presented two and 2 developed three ADRs. ADRs predisposition could be related to a prolonged exposure to more than one medication during hospitalization $^{10,21}$, and also to intrinsic biological factors typical of the pediatric age $\mathrm{e}^{22}$. In addition, we also found that younger children were more affected by ADRs than older ones. Analogous information was reported by Speranza et al..$^{23}$, and Aagaard et al ${ }^{24}$. For its part, a cuban study which included pediatric patients under 18 years of age found that the age range most affected by ADRs was between two and eleven years of age ${ }^{25}$. The difference between our results and the ones obtained in the previous study could be related to several things, such as patient's age, the defined age range and the number of patients included on it.

Our study only included children under 6 years of age divided in two age ranges ( $<2$ years and equal or $>2$ years of age). This was made considering the remarkable biological variability and physiological changes that occur in this age range.

We also found that males were more often affected by ADRs than females. Comparable results were reported by The WHO ICSR database (VigiBase ${ }^{\circledR}$ ), in which ADRs were predominantly present in males ${ }^{9,10}$. Nevertheless, other studies have shown higher ADRs frequency in females ${ }^{25,26}$.

The average length of hospitalization found was 7.1 days. Dos Santos and Coelho ${ }^{10}$ reported an average length of 18 hospitalization days. This discrepancy might be related to differences in the pediatrics services provided by the facilities in both studies. Unlike dos Santos and Coelho study, the hospitals enrolled in our study did not have specialized pediatric services. Hence, it could be argued that children having more complex pathologies might need a longer time of hospitalization for the treatment of their condition. Still, other studies have reported similar results to ours ${ }^{21}$. 
The average number of prescribed drugs in children with ADRs was similar to pediatric wards of European and non-European countries who have reported an average number higher than $5^{27}$. Systemic antibiotics and respiratory drugs were the therapeutic groups mostly associated with ADRs incidence. Antibiotic use was related to a higher risk of ADRs emergence, as reported by Oshikoyay et al. ${ }^{28}$, and Martinez-Mir et al. ${ }^{21}$, who found that antibiotics were the most common cause of ADRs. Other authors have also reported that ADRs are related with antibiotics use $\mathrm{e}^{10,21}$. As noted, antibiotics are not only the most prescribed class of drugs for hospitalized children, but also the ones that usually cause ADRs. We found that the most correlated ADRs associated with antibiotics were gastrointestinals. Therefore, the digestive system was the most affected by ADRs. This data is slightly consistent with evidence described by Sepahi et al. ${ }^{29}$, who found that the integumentary, gastrointestinal and central nervous systems were the ones most commonly affected by ADRs. In addition, skin and gastrointestinal ADRs are the most diagnosed and reported events in pharmacovigilance ${ }^{23,30}$.

Most of the ADRs found in our work were mild. These results differ with the findings of Shamna et $a .^{31}$, who found that moderate ADRs were the most common. In our study, Naranjo's algorithm classified the majority of ADRs found as probable, while Vallejos $^{32}$ reported that the majority of ADRs were possible and none was definite. However, it is extremely difficult to compare various studies, since the estimation of ADRs incidence is greatly influenced by the definitions used, the methodology of detection and classification and the study setting.

The main limitation of this study was the determination of imputability of adverse events. Despite patient daily monitoring, only $0.6 \%$ of ADRs found were labelled as definite. This was due to difficulties associated with case analysis by means of Naranjo's algorithm, since in order to accurately determine if an ADR is definite, drug readministration, placebo administration and drug serum levels lab tests must be carried out, which, in most cases, for ethical reasons, are not feasible. Moreover, in case of suspected ADRs, appropriate handling dictates that drugs must be suspended, which limits the ability to establish the remaining criteria for imputability determination. For these reasons, this study was purely observational and no intervention was made on patient's treatment by researchers.

Although we did not calculate a sample size due to difficulties in establishing the general population, an observation period of six months allowed us to establish an ADR incidence which resulted in similar findings to those reported in other studies ${ }^{10,21,24}$.

In addition, the detection of suspected ADRs was performed by a trained nurse. Even though physicians are the main notifiers of ADRs in practice, clinical research and pediatric pharmacovigilance ${ }^{24}$, it is clear that any health professional (physicians, nurses, pharmacists, dentists and others) can report suspected ADRs to pharmacovigilance systems. In addition, it should be noted that, due to the role nurses play in the administration and monitoring of therapy, they have a privileged position to detect drug effects, including $\mathrm{ADRs}^{33}$.

\section{Conclusions}

This is the first study that monitors ADRs in general pediatric wards in Colombia. Therefore, it is an important contribution to drug safety in children. This study establish the ADRs incidence density, frequency and characteristics on a defined time frame for enrolled children under 6 years of age. This provides an initial approximation to drug safety in children. In addition, these results demonstrate that ADRs in hospitalized children are common and represent an additional burden of morbidity and risk for these patients. Thus, extra costs are placed in the health care systems, which is an aspect that should be studied in the future.

The results obtained in this work are interesting not only for pharmacologist and pharmacoepidemiologist, but also for hospitals, medicine agencies, health care ministers, physicians, nurses and pediatricians. Hence, new programs should be developed to assess patient safety and the onset of adverse events during treatment and hospitalization.

Hence, it is necessary to develop proactive pharmacovigilance and patient safety programs with a focus in risk analysis and management, in which ADRs reporting should be mandatory. This measure might help us make our health care systems safer, especially for children, in which this topic must be further investigated.

Acknowledgements:

We thank "Universidad del Norte" (Barranquilla, Colombia) and the Department of Nursing for their cooperation in the development of this work. We are also grateful with the two participant hospitals, the nurses, the pediatricians and the pharmacist who collaborated during data collection and analysis.

Conflict of interest:

The authors declare no conflict of interest

Funding:

Departamento Administrativo de Ciencia, Tecnología e Innovación (Colciencias) Grant 566-2012, and Universidad del Norte

\section{References}

1. Walsh J, Mills S. Conference report: formulating better medicines for children: 4th European Paediatric Formulation Initiative conference. Ther Deliv. 2013; 4(1): 21-5.

2. Schirm E, Tobi H, de Vries TW, Choonara I, De Jong-van den Berg LT Lack of appropriate formulations of medicines for children in the community. Acta Paediatr. 2003; 92(12): 1486-9.

3. Hennessy S, Strom BL. PDUFA reauthorization--drug safety's golden moment of opportunity. N Engl J Med. 2007; 356: 1703-4.

4. Thiesen S, Conroy EJ, Bellis JR, Bracken LE, Mannix HL, Bird $\mathrm{KA}$, et al. Incidence, characteristics and risk factors of adverse drug reactions in hospitalized children - a prospective observational cohort study of 6,601 admissions. BMC Medicine. 2013; 11(1): 1-10.

5. Temple ME, Robinson RF, Miller JC, Hayes JR, Nahata MC. Frequency and preventability of adverse drug reactions in paediatric patients. Drug Saf. 2004; 27(11): 819-29. 
6. Bermúdez IB, Real N, Acosta JR, Rodríguez A. Farmacovigilancia intensiva en pacientes adultos y pediátricos. Rev Cubana Farm. 1999; 33(2): 111-5.

7. OPS . Buenas prácticas de Farmacovigilancia de las Américas. Documento Técnico No. 5. Washintong D.C.: Red Panamericana de Armonización de la Reglamentación Farmacéutica; 2011. Accessed: 1 April 2016. Available from: http://apps.who.int/ medicinedocs/documents/s18625es/s18625es.pdf.

8. The Uppsala Monitoring Centre . Glossary of terms used in Pharmacovigilance.Uppsala; 2011. Accessed: 1 April 2016. Available from: http://who-umc.org/Graphics/24729.pdf.

9. Star K, Noren GN, Nordin K, Edwards IR. Suspected adverse drug reactions reported for children worldwide: an exploratory study using VigiBase. Drug Saf. 2011; 34(5): 415-28.

10. dos Santos DB, Coelho HL. Adverse drug reactions in hospitalized children in Fortaleza, Brazil. Pharmacoepidemiol Drug Saf. 2006; 15(9): 635-40.

11. Belén Rivas A, Arruza L, Pacheco E, Portoles A, Diz J, Vargas E. Adverse drug reactions in neonates: a prospective study. Arch Dis Child. 2016; 101: 371-6.

12. International Conference on Harmonisation (ICH). Postapproval safety data management: definitions and standards for expedited reporting E2D-2003. Accessed: 1 April 2016. Available from: http://www.ich.org/fileadmin/Public Web Site/ICH Products/Guidelines/Efficacy/E2D/Step4/E2D Guideline.pdf.

13. Naranjo C, Busto U, Sellers E, Sandor P, Ruiz I, Roberts E, et al. A method for estimating the probability of adverse drug reactions. Clin Pharmacol Ther. 1981; 30(2): 239-45.

14. Naranjo CA, Shear NH, Lanctot KL. Advances in the diagnosis of adverse drug reactions. J Clin Pharmacol. 1992; 32(10): 897-04.

15. Hartwig SC, Siegel J, Schneider PJ. Preventability and severity assessment in reporting adverse drug reactions. Am J Hosp Pharm. 1992; 49(9): 2229-32.

16. Schumock GT, Thornton JP. Focusing on the preventability of adverse drug reactions. Hosp Pharm. 1992; 27(6): 538.

17. Ceci A, Giaquinto C, Aboulker JP, Baiardi P, Bonifazi F, Della Pasqua $\mathrm{O}$, et al. The Task-force in Europe for Drug Development for the Young (TEDDY) Network of Excellence. Paediatr Drugs. 2009; 11(1): 18-21.

18. WHO . ATC/DDD Index. WHO Collaborating Centre for Drug Statistics Methodology; 2013. Accessed: 1 April 2016. Available from: http://www.whocc.no/atc_ddd_index/?code=M01.

19. Turner S, Nunn AJ, Fielding K, Choonara I. Adverse drug reactions to unlicensed and off-label drugs on paediatric wards: a prospective study. Acta Paediatr. 1999; 88(9): 965-8.

20. Jimenez R, Smith A, Carleton B. New Ways of Detecting ADRs in Neonates and Children. Curr Pharm Des. 2015; 21(39): 5643-9.
21. Martinez-Mir I, Garcia-Lopez M, Palop V, Ferrer JM, Rubio E, Morales-Olivas FJ. A prospective study of adverse drug reactions in hospitalized children.Br J Clin Pharmacol. 1999; 47(6): 681-8.

22. Alomar MJ. Factors affecting the development of adverse drug reactions. Saudi Pharm J. 2014; 22(2): 83-94.

23. Speranza N, Lucas L, Telechea H, Santurio A, Giachetto G, Nanni L. Reacciones adversas a medicamentos en niños hospitalizados: un problema de salud pública. Rev Méd Uruguay. 2008; 24(3): 161-6.

24. Aagaard L, Weber CB, Hansen EH. Adverse drug reactions in the paediatric population in Denmark: a retrospective analysis of reports made to the Danish Medicines Agency from 1998 to 2007. Drug Saf. 2010; 33(4): 327-39.

25. Furones Mourelle JA, Cruz Barrios MA, López Aguilera ÁF, Martínez Núñez D, Alfonso Orta I. Reacciones adversas por antimicrobianos en niños de Cuba.Rev Cubana Med Gen Integral. 2015; 31(2): 205-16.

26. Li H, Guo X-J, Ye X-F, Jiang H, Du W-M, Xu J-F, et al. Adverse Drug Reactions of Spontaneous Reports in Shanghai Pediatric Population. PLoS One.2014;9(2): e89829.

27. Rashed A, Wong IK, Cranswick N, Tomlin S, Rascher W, Neubert A. Risk factors associated with adverse drug reactions in hospitalised children: international multicentre study. European J Clin Pharmacol. 2012; 68(5): 801-10.

28. Oshikoya KA, Chukwura H, Njokanma OF, Senbanjo IO, Ojo I. Incidence and cost estimate of treating pediatric adverse drug reactions in Lagos, Nigeria. Sao Paulo Med J. 2011; 129(3): 153-64.

29. Sepahi M, Movahed Z, Heydari H, Shirkhodai M, Shokrollahi M. Surveillance of adverse drug reaction in hospitalized children, a cross sectional study from Qom Province, Iran. Life Sci J. 2013; 10(12s): 122-5.

30. Star K, Edwards IR. Pharmacovigilance for children's Sake. Drug Safety. 2014; 37(2): 91-8.

31. Shamna M, Dilip C, Ajmal M, Linu Mohan P, Shinu C, Jafer CP, et al. A prospective study on adverse drug reactions of antibiotics in a tertiary care hospital. Saudi Pharmaceutical J. 2014;22(4):303308.

32. Vallejos A. Reacciones Adversas por antibióticos en una Unidad de Cuidado Intensivo Pediátrico y Neonatal de Bogotá. Biomédica. 2007; 27:66-75.

33. Pinheiro LF, Franca CN, Izar MC, Barbosa SP, Bianco $\mathrm{HT}$, Kasmas SH, et al. Pharmacokinetic interactions between clopidogrel and rosuvastatin: Effects on vascular protection in subjects with coronary heart disease. Int J Cardiol. 2012; 158(1): $125-9$. 